

\section{DISCLAIMER}

This report was prepared as an account of work sponsored by an agency of the United States Government. Neither the United States Government nor any agency Thereof, nor any of their employees, makes any warranty, express or implied, or assumes any legal liability or responsibility for the accuracy, completeness, or usefulness of any information, apparatus, product, or process disclosed, or represents that its use would not infringe privately owned rights. Reference herein to any specific commercial product, process, or service by trade name, trademark, manufacturer, or otherwise does not necessarily constitute or imply its endorsement, recommendation, or favoring by the United States Government or any agency thereof. The views and opinions of authors expressed herein do not necessarily state or reflect those of the United States Government or any agency thereof. 


\section{DISCLAIMER}

Portions of this document may be illegible in electronic image products. Images are produced from the best available original document. 
UCRL-ID--111453

DE93 001324

\title{
Effects of Ionizing Radiation on Selected Optical Materials: An Overview
}

\author{
G. Richard Wirtenson and Richard H. White \\ University of California \\ Lawrence Livermore National Laboratory \\ P.O. Box 808, L-298 \\ Livermore, CA 94550
}

\begin{abstract}
This report gives an overview of the effects of ionizing radiation on optical materials that may be used in spacecraft sensors. It introduces the relevant phenomena and indicates where more detailed information can be found. The topics covered include radiation induced absorption in ultraviolet transmitting materials, ordinary optical glasses, cerium stabilized optical glasses, and infrared transmitting materials; bleaching and annealing, and radioluminesence.
\end{abstract}

\section{INTRODUCTION}

We give an overview of the effects of ionizing radiation on optical materials that may be of interest in connection with spacecraft sensors. Our aim is to acquaint the reader with the underlying concepts, give the range of controlling parameters, and indicate where more quantitative information can be found.

The material presented is a compilation of information gleaned from various sources. In several places we have paraphrased or edited the original authors' texts and we have tried to give accreditation where appropriate.

\section{TYPES OF RADIATION [Wild (1991b), Levy (1985)]}

The effect of ionizing radiation on the optical transmissivity of irradiated materials, to a large extent, depends only on the dose delivered ${ }^{1}$, regardless of the type of radiation exposure. The primary effect of the radiation is to cause ionization of the irradiated material; the amount of ionization and the

\footnotetext{
${ }^{1}$ Dose is the energy absorbed per unit mass; the term is used for all kinds of radiation: gammas, electrons, protons, and neutrons... It is measured in rads or Grays (Gy): $1 \mathrm{rad}=100 \mathrm{erg} / \mathrm{g}, 1 \mathrm{~Gy}=1 \mathrm{~J} / \mathrm{kg}=100 \mathrm{rad}$.
}

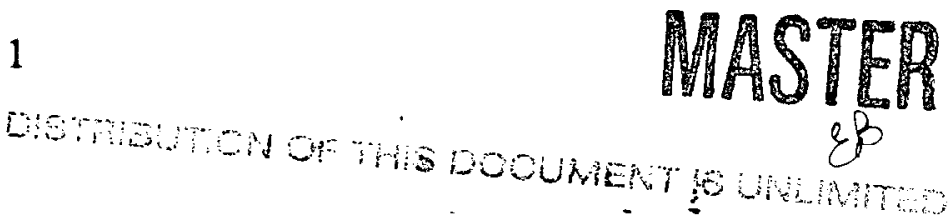


energies of the ejected photo-electrons or Compton recoil electrons depend mainly upon the total energy producing these effects, independent of the source of the energy. Once the ejected electrons and/or recoil electrons are created, they interact with the solid matter in the same ways as any other energetic electrons and so their effects are independent of the source.

There are exceptions to the above noted equivalence of various types of radiation in their effect on optical materials. These exceptions occur at such high fluence or dose levels that they are probably not of concern in spacecraft environments. Neutrons may produce a large amount of (ion) displacement damage. Electrons also produce displacement damage but this is significant only at high dose levels $\left(>10^{8} \mathrm{rad}\right)$. Protons produce significant ion displacement damage for fluences above $10^{10}$ to $10^{12}$ particles per $\mathrm{cm}^{2}$. Well ordered crystals may be more susceptible to displacement damage and therefore may be affected by lower doses.

Charged particles may produce other effects associated with their charge. For example, when electrons have a range less than the thickness of the irradiated material, charge is deposited into the material and additional effects such as static discharge and the formation of Lichtenburg trees can occur. Such charge associated effects are commonly seen when electron accelerators are used as radiation sources in materials testing but are less likely to be of concern in connection with spacecraft optics systems.

\section{RADIATION INDUCED ABSORPTION}

Optical materials may darken when exposed to ionizing radiation. This darkening is attributed to electrons (or holes) that are trapped in inherent defect sites and also to the creation of new defect sites by the ionizing radiation. The darkening has been modeled as follows:

$$
T(\lambda, D, x)=T_{0} e^{-\alpha_{0} x}
$$

where $T$ is the transmission at wavelength $\lambda$ through an optical path length $x$ of material that has received an accumulated radiation dose $D, T_{0}$ is the transmission before irradiation, and $\alpha_{D}$ is the radiation induced absorption coefficient:

$$
\alpha_{D}=\alpha_{s a t}\left(1-e^{-\beta D}\right)+K D
$$

where $\alpha_{\text {sat }}$ ("saturation" value of $\alpha$ ), $\beta$, and $\mathrm{K}$ are independent of dose but depend on material and wavelength. The term with $\alpha_{\text {sat }}$ and $\beta$ describes absorption due to the population of inherent defect sites. The term with $\mathrm{K}$ (linear in $\mathrm{D}$ ) describes absorption associated with the formation of new defect sites (ion displacement). This term can generally be ignored for doses $<10^{8} \mathrm{rad}$. (Coakley 1992)

For small doses $(D<<1 / \beta)$ the exponential can be expanded to first order in $D$ :

$$
\alpha_{D}=\beta \alpha_{s a t} D \quad[D \ll 1 / \beta]
$$

For common optical glasses and wavelengths in the visible and near infrared, values of $\beta$ range from $\sim 5 \times 10^{-7}$ to a few times $10^{-5} \mathrm{rad}^{-1}$ and $\alpha_{\text {sat }}$ ranges from near 0 to $\sim 20 \mathrm{~cm}^{-1}$. The values of $\beta$ depend 
upon the material but tend to be only slightly dependent on wavelength; the values of $\alpha_{\text {sat }}$ depend strongly on both material and wavelength. Information for specific materials can be found in Treadaway (1975a,b) Schott (c1990), and Levy (1985).

Treadaway, Passenheim, and Kitterer (Treadaway 1975a,b) also report that darkening may depend on dose rate. They note that for two Schott glasses: SF 10 and SF 11, dose rate dependence was not observed for exposure at $4.5 \times 10^{4} \mathrm{rad} / \mathrm{s}$ but was dramatic at $2.5 \times 10^{5} \mathrm{rad} / \mathrm{s}$ and that darkening was less when the samples were exposed at the higher rates. (Norb Wild suggests that this may be due to radiation induced conductivity.)

\section{A. Quartz, Fused Silica, and Sapphire: Ultraviolet Transmitting Materials}

Quartz, Fused Silica, and Sapphire show little darkening upon exposure to ionizing radiation. Treadaway $(1975 \mathrm{a}, \mathrm{b})$ reports that the darkening for these materials is less than $1 \%$ of that for the common optical glasses.

\section{B. Ordinary Optical Glasses}

Optical glasses are non-crystalline, inorganic mixtures of various metallic oxides, fused by heating with materials such as silica or boric or phosphoric oxides. The oxides are blended to vary the refractive indices and alter the dispersion, and so to produce glasses with various desired optical properties. The Schott Optical Glass Catalogue (Schott c1980) contains 27 different glass categories such as "crown" or "flint" with over 240 specific glass types, such as "borosilicate crown -7" (BK 7). Optical glass types in this report are all specified with the designation used by Schott Optical Co. Unless stabilized by the addition of cerium, optical glasses tend to be noticeably darkened by doses of a few thousand rads.

\section{Cerium Stabilized Optical Glasses}

Multi-valence cerium ions can accept either electrons or holes and so the addition of cerium to glasses inhibits trapping of electrons or holes at defect sites and stabilizes the glass against darkening by ionizing radiation. According to Stroud $(1966) \mathrm{Ce}^{3+}$ ions capture holes to form $\mathrm{Ce}^{3++}$ centers and $\mathrm{Ce}^{4+}$ ions capture electrons to form ( $\mathrm{Ce}^{4+}+$ electron) centers. (Stroud includes an extensive list of references on radiation induced color centers in glasses.)

There is a penalty to pay for this stabilization: the cerium ions themselves act as color centers and cause the stabilized glasses to be more absorptive than ordinary glasses. This penalty is large for ultraviolet and short visible wavelengths but usually small for intermediate visible and infra-red wavelengths. After radiation exposure, the ordinary glasses become more absorptive at all wavelengths whereas the stabilized glasses tend to retain their transmissivity at visible and infra-red wavelengths.

Radiation resistant glasses should be considered if the total anticipated dose exceeds $1 \mathrm{krad}$ or the dose rate exceeds $5 \mathrm{rad} / \mathrm{h}$. Schott offers a number of cerium stabilized radiation resistant glasses. These are listed in Table I. Optical glasses that contain cerium oxide have a "G" in their designation and a number that is ten times the percentage content of cerium oxide. For example BaK $1 \mathrm{G} 12$ contains $1.2 \%$ $\mathrm{CeO}_{2}$. Table I also shows which of the radiation resistant glasses have been tested for radiation resistance under exposure to electrons, proton, neutrons, and gammas. Test results are reported in [Schott (c1990)]. Treadaway $(1975 \mathrm{a}, \mathrm{b})$ reports that after exposure to $4.5 \times 10^{8} \mathrm{rad}$, Schott BK 7 G14 (not included in Table I) showed no measurable induced absorption.

Stroud (1966) notes that charge capture is not unique to cerium: " $\mathrm{Ti}^{3+}, \mathrm{Mn}^{2+}$ and $\mathrm{Fe}^{2+}$ ions all capture holes and many other elements have charge capturing states. Probably the low oxidation states capture holes and the high oxidation states capture electrons." Radiation stabilization may be achieved by the addition of elements other than cerium to the composition of a glass. 
Table I: Schott Radiation Resistant Glasses and Radiation Tests Conducted on Them.

(Bullets mean tests have been done for indicated radiation type.)

\begin{tabular}{|c|c|c|c|c|c|c|}
\hline \multirow{3}{*}{ Glass Type } & \multicolumn{6}{|c|}{ Type of Radiation Testing } \\
\hline & \multirow[b]{2}{*}{$\mathrm{e}^{-}$} & \multirow[b]{2}{*}{ p } & \multirow[b]{2}{*}{$\mathbf{n}$} & \multicolumn{3}{|c|}{$\gamma \mathrm{Co}^{60}$} \\
\hline & & & & $\begin{array}{l}10^{6} \\
\mathrm{rad}\end{array}$ & $\begin{array}{l}10^{7} \\
\mathrm{rad}\end{array}$ & $\begin{array}{l}10^{8} \\
\mathrm{rdd}\end{array}$ \\
\hline $\begin{array}{l}\text { BK } 7 \text { G18 } \\
\text { BK } 7 \text { G25 } \\
\text { K } 5 \text { G20 } \\
\text { BaK } 1 \text { G12 } \\
\text { SK } 4 \text { G13 } \\
\text { SK } 5 \text { GO6 } \\
\text { SK10 G10 } \\
\text { SSK 5 G06 } \\
\text { LaK } 9 \text { G15 } \\
\text { LF 5 G15 } \\
\text { F } 2 \text { G12 } \\
\text { SF } 5 \text { G10 } \\
\text { SF } 6 \text { G05 } \\
\text { SF 8 G07 } \\
\text { KzFS } 4 \text { G20 } \\
\text { GG } 375 \text { G34 }\end{array}$ & $\begin{array}{l}\bullet \\
\bullet \\
\bullet\end{array}$ & • & $\begin{array}{l}\bullet \\
: \\
: \\
: \\
\bullet\end{array}$ & $\begin{array}{l}: \\
: \\
: \\
: \\
: \\
: \\
: \\
:\end{array}$ & $\begin{array}{l}: \\
: \\
: \\
: \\
: \\
: \\
:\end{array}$ & $\begin{array}{l}: \\
: \\
: \\
: \\
: \\
: \\
:\end{array}$ \\
\hline
\end{tabular}

Radiation resistant glasses are available for a large range of refractivities and dispersivities. The chart below (Fig. 1) shows the refractive index, $n_{d}$, and Abbe number, $v_{d}$, for the glasses listed in. Table I as well as for a number of special order glasses.

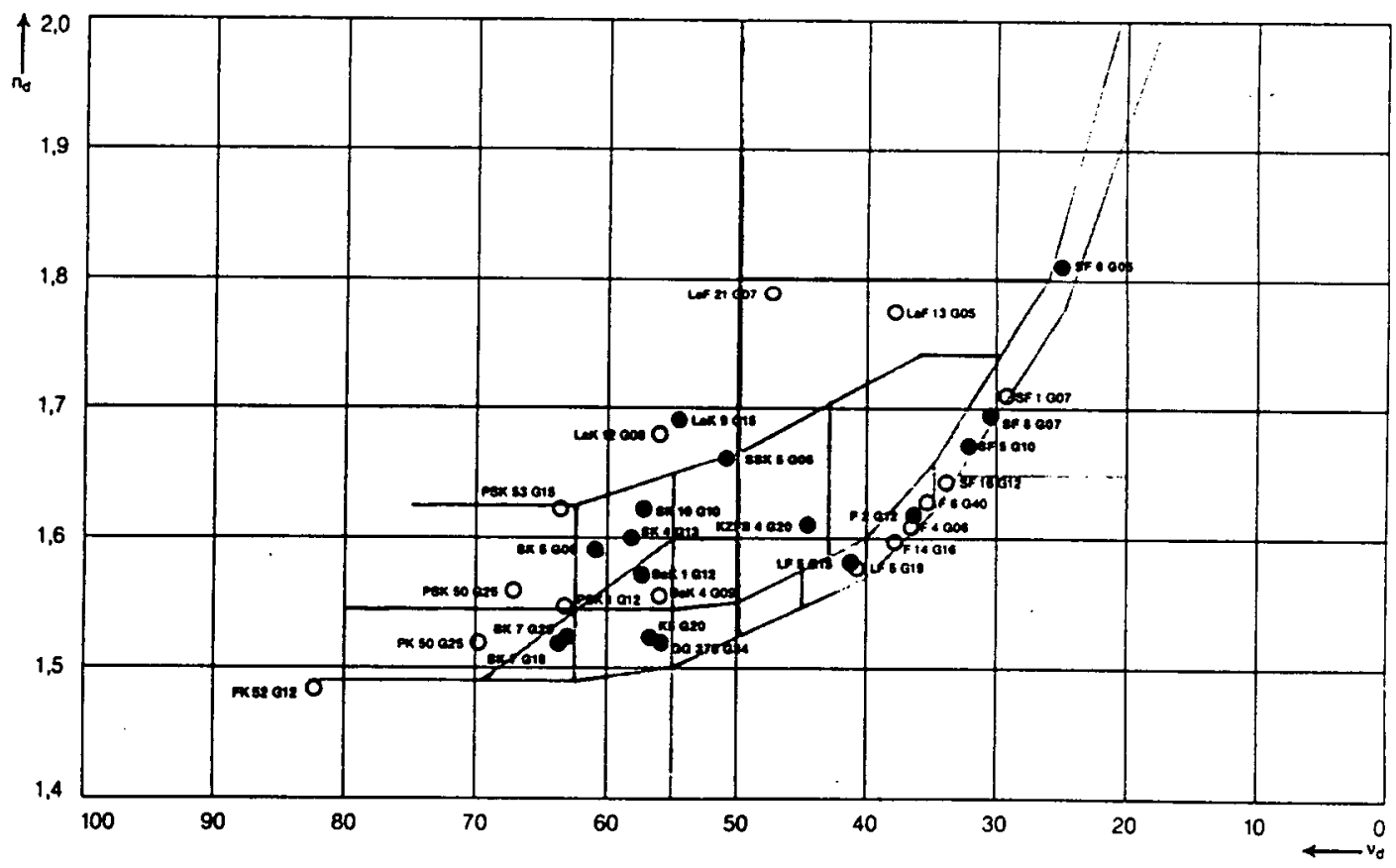

Fig. 1 Refractive index, $\mathrm{n}_{\mathrm{d}}$, and Abbe number, $\mathrm{v}_{\mathrm{d}}$, for various Schott Optical Glasses

- Available Glasses, ${ }^{\circ}$ Special Order 
Figure 2a shows calculations of the darkening effect of ionizing radiation on a typical optical system if it employs unstabilized glass optical elements: Schott SF $10(.604 \mathrm{~cm})$ and SK $14(1.714 \mathrm{~cm})$. This configuration of glasses simulates an unstabilized version of an all refracting, wide-field-of view, lens in a "Startracker" spacecraft navigational sensor system. ${ }^{2}$ Figure $2 \mathrm{~b}$ shows similar calculations on the same system but with cerium stabilized glasses: Schott SF 6 G5 $(.825 \mathrm{~cm})$ and LaK $9 \mathrm{G} 15(1.85 \mathrm{~cm})$, used in the optical elements.

The calculations assume that each optical element receives the full dose. The dose will be reduced by enclosures and filters. Treadaway (1975a,b) suggests using quartz, sapphire, or cerium doped glass as the first element in optical systems to protect the optics from receiving the full flux from the spacecraft environment. (See section IVA above)

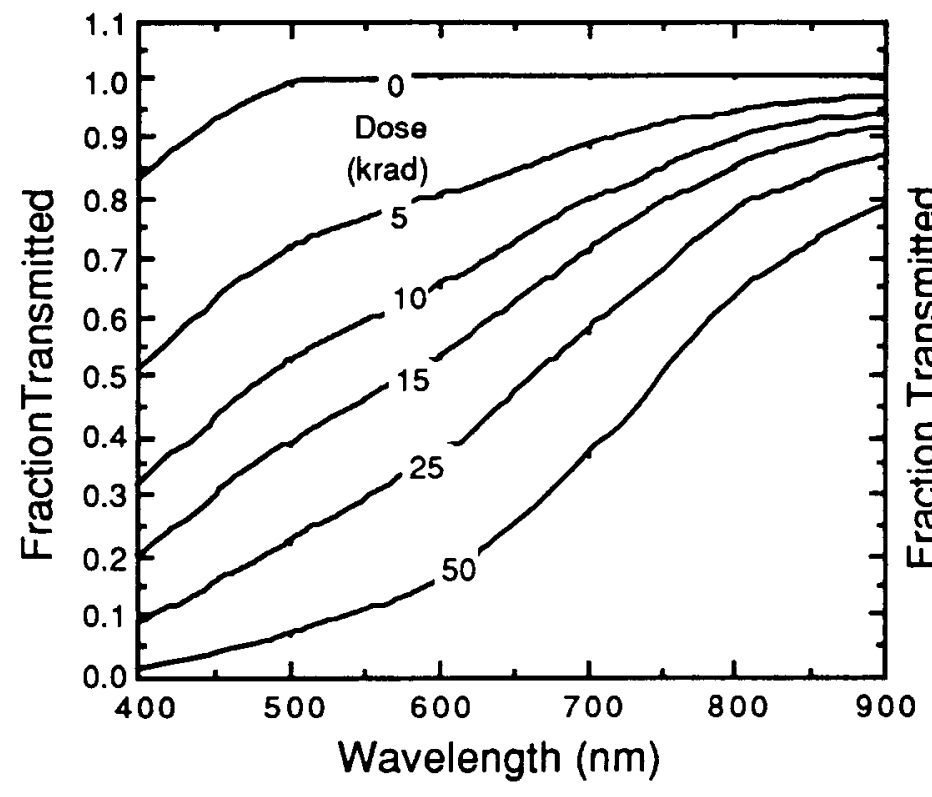

Fig. 2a: Effect of Ionizing Radiation on Startracker Optics System (Unstabilized Glasses)

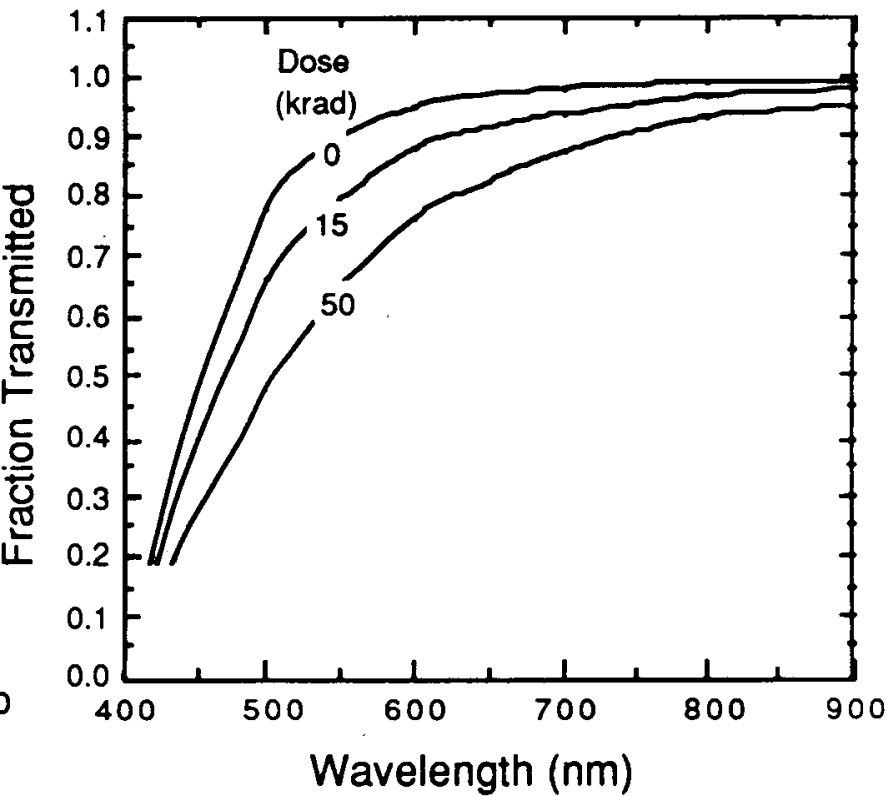

Fig. 2b: Effect of Ionizing Radiation on Startracker Optics System (Cerium Stabilized Glasses)

${ }^{2}$ Radiation induced absorption parameters for some glasses have not been measured and so similar glasses were substituted in the model. Data for the Startracker optical components are being measured, at LLNL, for both stabilized and unstabilized designs, and will be reported elsewhere. No fiber optics are included in the calculation. 


\section{Silicon, Germanium, and other Infrared Transmitting Materials [Wild (1991a)]}

Silicon and germanium are two logical choices for infrared $(2-20 \mu \mathrm{m})$ transmissive optics. Both have relatively flat spectral transmittance bands. $2 \mathrm{~mm}$ of $S i$ is about $55 \%$ transmissive from 2 to $6 \mu \mathrm{m}$ but can be used to about $10 \mu \mathrm{m}$. Ge is useful for wavelengths from 2 to $20 \mu \mathrm{m}$ but its transmittance is less than for $\mathrm{Si}: 40-50 \%$ through $2 \mathrm{~mm}$ of material. These relatively low transmittance values are attributed to the high refractive indices of these materials and the resultant Fresnel reflection losses at the air-substrate interface. Optical coatings can increase the overall transmittance to values in excess of $90 \%$ average with maxima reaching $\mathbf{9 8 \%}$ for some wavelengths. These coatings are typically of the order of a few microns or less and hence radiation induced absorption in the coating material is small.

Other infrared transmitting materials that may be of interest are sapphire $(0.18-6.5 \mu \mathrm{m}), \mathrm{ZnSe}(0.5-$ $14 \mu \mathrm{m}), \mathrm{ZnS}(0.5-12 \mu \mathrm{m}), \mathrm{CaF}_{2}(0.15-12 \mu \mathrm{m})$, and $\mathrm{BaF}_{2}(0.3-12 \mu \mathrm{m})$. The alkali halides are good infrared transmitters but are hygroscopic.

Data on radiation effects on the above named materials is sparse. However, for dose levels up to $10 \mathrm{Mrad}$, observed radiation induced absorptance $\left(\alpha_{D}\right)$ is generally less than $0.02 \mathrm{~cm}^{-1}$ for wavelengths greater than $1 \mu \mathrm{m}$. A summary of experiments is found in Wild 1991a.

\section{BLEACHING AND ANNEALING [Treadaway (1975a,b)]}

In most glasses, radiation-induced darkening fades with time. The rate of fading depends upon the material and wavelength. This effect is called bleaching if the color center is depopulated (a trapped electron or hole is thermally activated out of the center); it is called annealing if the defect center is removed by rearrangement of the ions surrounding the defect. Here we follow Treadaway $(1975 a, b)$ and ignore the distinction and refer to both processes as bleaching.

Treadaway $(1975 \mathrm{a}, \mathrm{b})$ separates bleaching into two time domains. The period from 1 to $90 \mathrm{sec}$ after irradiation they call "intermediate-time." Here the absorption is observed to decrease exponentially with time with typical lifetimes of 20 to 30 seconds for the optical glasses listed in Table 1. Recovery is not complete. Reported values range from 10\% (Schott UBK 7) to 75\% (Schott BaK 4).

Beyond 90 seconds after irradiation, the (long term) bleaching rate is described by a relation obtained from curve fits to experimental data:

$$
\alpha(t)=\alpha_{90}(A-B \ln t) \quad\left(90 \mathrm{~s}<t<6 \times 10^{4} \mathrm{~s}\right)
$$

where $\alpha_{90}$ is the radiation induced absorption coefficient measured 90 seconds after irradiation (assuming the irradiation time is much shorter than the bleaching time); the coefficients A and B depend upon material and wavelength but not on dose. Table II gives the values of A and B reported in Treadaway (1975a,b) for 9 commonly used Schott optical glasses.

Bleaching can be accelerated by exposing the darkened material to light or by heating it. (Conversely, it is likely that the reduced temperatures and light intensities anticipated for a spacecraft optics system may decelerate bleaching.) Data on bleaching acceleration is sparse. Some is reported in Treadaway $(1975 a, b)$. 
Table II: Bleaching Parameters

(Treadaway 1975a,b)

\begin{tabular}{|c|c|c|c|c|c|c|}
\hline \multirow{2}{*}{ Glass Type } & \multicolumn{3}{|c|}{ Intermediate Term Bleaching } & \multicolumn{3}{c|}{$\begin{array}{c}\text { Long Term Bleaching } \\
\text { (Eq. 4: A \& values for } \mathrm{t} \text { in s.) }\end{array}$} \\
\cline { 2 - 7 } & $\begin{array}{c}\text { Wavelength } \\
(\mathrm{nm})\end{array}$ & $\begin{array}{c}\text { Lifetime } \\
(\mathrm{s})\end{array}$ & $\begin{array}{c}\text { Recovery } \\
(\%)\end{array}$ & $\begin{array}{c}\text { Wavelength } \\
(\mathrm{nm})\end{array}$ & $\mathrm{A}( \pm 5 \%)$ & $\mathrm{B}( \pm 8 \%)$ \\
\hline \multirow{2}{*}{ BaK 4 } & 500 & 30 & 75 & 600 & 1.4 & .088 \\
& & & & 800 & 1.3 & .089 \\
BK 7 & 500 & 28 & 45 & 500 & 1.3 & .063 \\
& & & & 600 & 1.3 & .063 \\
UBK 7 & 380 & 30 & 21 & 500 & 1.3 & .056 \\
& 500 & 30 & 10 & 600 & 1.2 & .048 \\
LaK 10 & 380 & 30 & 16 & 500 & 1.4 & .096 \\
& 500 & 26 & 19 & 600 & 1.4 & .091 \\
& & & & 800 & 1.3 & .076 \\
KzFSN 4 & 380 & 44 & 21 & 500 & 1.4 & .091 \\
& 500 & 30 & 21 & 600 & 1.4 & .093 \\
& & & & 800 & 1.3 & .074 \\
SK 7 & 380 & 28 & 15 & 400 & 1.3 & .069 \\
& 500 & 24 & 27 & 500 & 1.4 & .084 \\
& & & & 600 & 1.4 & .084 \\
SK 14 & 380 & 20 & 18 & 500 & 1.3 & .074 \\
& 500 & 24 & 36 & 600 & 1.3 & .074 \\
SF 10 & 500 & 25 & 60 & 400 & 1.4 & .091 \\
SF 11 & 380 & 30 & 32 & 400 & 1.4 & .087 \\
& 500 & 27 & 74 & & \\
\hline
\end{tabular}

\section{RADIOLUMINESCENCE}

In addition to the darkening effects discussed in section III, ionizing radiation may cause optical elements to luminesce. According to Treadaway, Passenheim, and Kitterer (Treadaway 1975a,b) luminescent intensities may be high enough to "cause an increase optical noise, flash blindness of photo detectors, or, in extreme cases, detector failure."

Treadaway $(1975 \mathrm{a}, \mathrm{b})$ reports that crystalline quartz displayed an intense band of radioluminesence peaking near a wavelength of $185 \mathrm{~nm}$ with full width at half maximum (fwhm) of $\sim 40 \mathrm{~nm}$, and a much weaker band near $285 \mathrm{~nm}$. They report that the radioluminescence spectrum of fused silica (Suprasil-2) is almost identical to that of the crystalline quartz. They found that Schott BK7-G14 had a broad luminescence band peaking at about $420 \mathrm{~nm}$ with fwhm $\sim 100 \mathrm{~nm}$. And they found that Sapphire had a band peaking near $250 \mathrm{~nm}$ with fwhm $\sim 60 \mathrm{~nm}$ and a narrow sharp peak at $696 \mathrm{~nm}$. ${ }^{3}$ They believe the

\footnotetext{
${ }^{3}$ They attempted spectral measurements on unstabilized Schott glasses and comment: "Since Schott glasses, except BK7-G14, darkened significantly in the time necessary to scan the monochromator, determination of the spectral dependence of the radioluminescence from these samples could not be made with our apparatus..." They suggest that higher fluxes delivered in short pulses (as e.g. with a linear accelerator) would produce luminescence spectra without the darkening associated with high dose levels.
} 
radioluminecence from BK7 G14 is attributable to the cerium impurity. This suggests this same luminescence would be observed in other cerium stabilized glasses

Figure 3 is adapted from Treadaway (1975a) and shows the luminescence intensites for sapphire, crystalline quartz, fused silica (Suprasil-2), Schott BK7, Schott BK7 G14, and Schott SF 10 as functions of dose rate. Treadaway (1975a) presents data for other glasses as well.

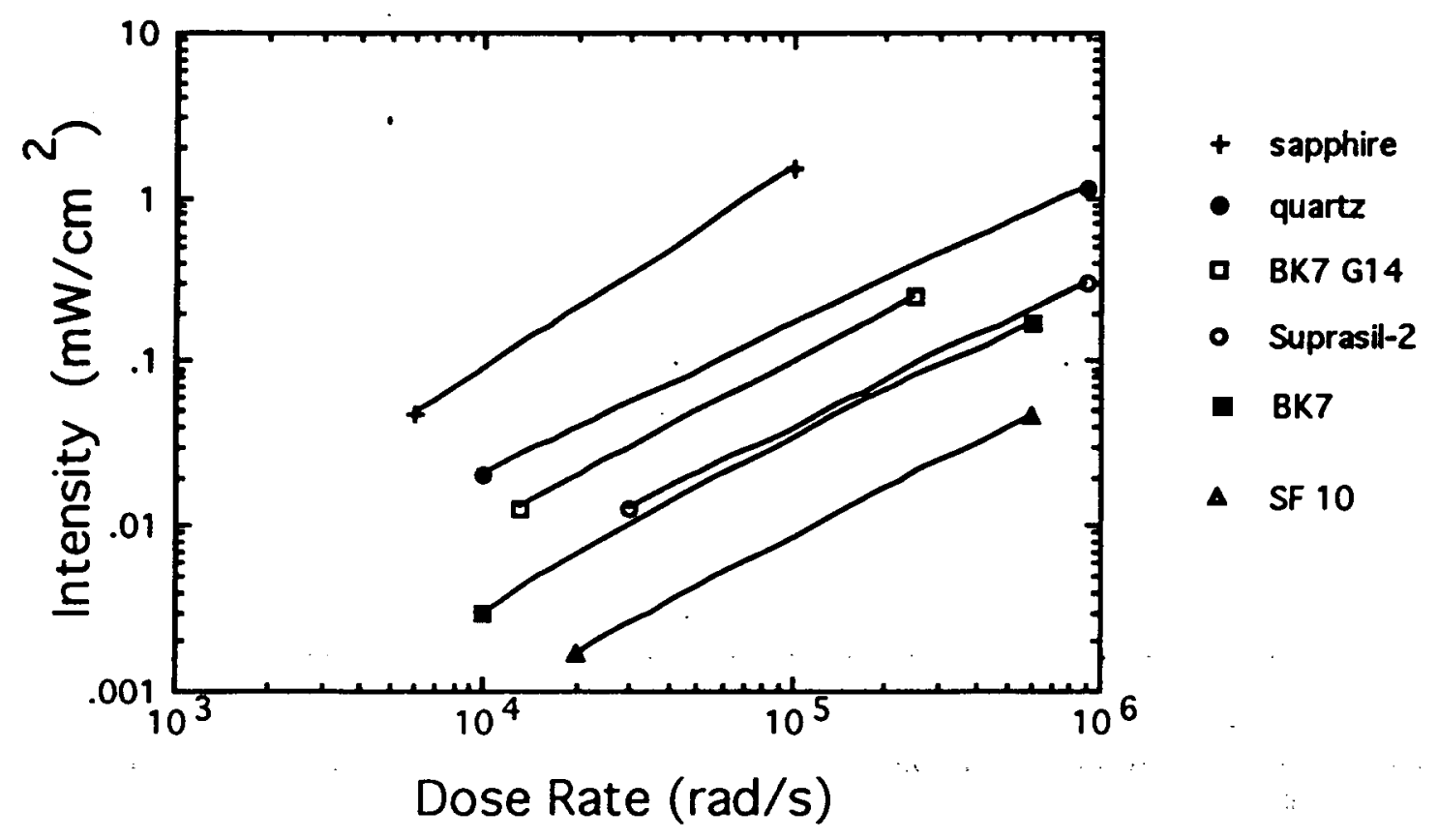

Fig. 3: Radiouluminsence intensity vs. dose rate for selected optical materials. [Treadaway (1975a)]

\section{ACKNOWLEDGEMENTS}

We are grateful to the staff at JAYCOR for the wealth of information they have supplied. In particular, we thank both Peter Coakley and Norb Wild for supplying copies of various reports as well as for their verbal and written comments. We thank Dr. Nicholas Colella for his constructive suggestions. 


\section{REFERENCES}

Coakley (1992) Peter Coakley/JAYCOR, Private Communication

Levy (1985). P. Levy, SPIE transactions: Radiation Effects in Optical Materials Vol. 541 p 2-24 (1985)

Schott(c1980) "Optical Glass, No. 3111" catalogue available from Schott Optical Glass, Duryea Pa.

Schott (c1990) "Radiation Resistant Glasses" brochure available from Schott Optical Glass, Duryea Pa.

Stroud(1966) J.S. Stroud, J.W.H. Schreurs and R.F. Tucker "Charge Trapping and the Electronic Structure of Glass" Proc, of the VII International Congress on Glass (Brussels, 1965), Gordon and Breach, N.Y. (1966)

Treadaway (1975a) M.J. Treadaway, B.C. Passenheim and B.D. Kitterer "Transient Radiation Effects in Optical Materials" Intelcom Rad Tech Inc. Report No. SAMSO-TR-75-174. This is a very thorough and information packed report on a series of experiments that addressed particularly the study of the effects of radiation on optical materials of interest in connection with spacecraft.

Treadaway (1975b) M.J. Treadaway, B.C. Passenheim, and B.D. Kitterer "Luminescence and Absorption of Electron-Irradiated Common Optical Glasses, Sapphire, and Quartz" IEEE Transaction on Nuclear Science, Vol. NS-22, December 1975. This article summarizes much of the material reported in Treadaway (1975a) and is more readily available.

Wild (1991a) Norb Wild/JAYCOR "Radiation Effects on Si and Ge and other IR Materials" Memorandum to Dick Wirtenson/LLNL (July 15 1991).

Wild (1991b) Norb Wild/JAYCOR "Radiation Effects Testing - Electrons vs. Gammas" Memorandum to Dick Wirtenson/LLNL (July 24, 1991). 